\title{
Alteration in Antioxidant Defence System and Oxidative Stress in blood of Liver Cirrhosis
}

\author{
A.P. Thakkar ${ }^{1}$, H.J. Shah ${ }^{2 *}$, N.D. Patel ${ }^{3}$ \\ ${ }^{1,2}$ Dept. of Biochemistry, M. B. Patel Science College, Affiliated to Sardar Patel University, Anand, India \\ ${ }^{3}$ Jiwandeep Hospital, Anand, India \\ *Corresponding Author:, hjsapt@gmail.com
}

Available online at: www.isroset.org

Received: 10/Jan/2019, Accepted: 11/Feb/2019, Online: 28/Feb/2019

\begin{abstract}
Serum liver marker enzymes ALT, AST, ALP and GGT are generally used as liver marker enzymes however they cannot provide exact idea regarding establishment of liver disease condition because many liver cirrhotic participants indicate non-significant alteration. Present study is aimed to know the level of antioxidant defense system and oxidative stress in controls and cirrhotic participants. The cross-sectional study was carried out at tertiary centre of gastroenterologist unit at Anand. Experimental participants were divided into two groups: Control ( $\mathrm{n}=52$, Age- $26.7 \pm 1.23$ years, $39 \mathrm{M} / 13 \mathrm{~F})$ and cirrhosis $(n=44$, Age- 53.48 \pm 2.02 years, $34 \mathrm{M} / 10 \mathrm{~F})$. All participants underwent anthropometric assessment, clinical examination, biochemical parameters, antioxidant parameters and lipid peroxidation marker or oxidative stress marker. Results of our study indicates non- conclusive increase in serum enzyme level. As an average only $42-67 \%$ of the participants indicates increase (ALT (55\%), AST (67.5\%), GGT (57.5\%) and ALP (42.5\%)). The total antioxidant activity (Gallic acid equivalent (GAE $(\mathrm{p}<0.0001)$ ) and Trolox equivalent $(\mathrm{TE})(\mathrm{p}<0.0001))$ and antioxidant enzymes such as Catalase (CAT $(\mathrm{p}<0.0001))$, Glutathione Peroxidase (GSHPx $(\mathrm{p}<0.0001))$ and Glutathione-s-transferase (GST $(\mathrm{p}<0.0001))$ were significantly decreased except superoxide dismutase (SOD $(\mathrm{p}<0.05)$ ) during cirrhosis condition. Lipid peroxidation marker or oxidative stress marker (MDA) was significantly increased $(\mathrm{p}<0.0001)$ in cirrhotic participants compared to controls. The alteration in the above parameters is among all (100\%) the participants. Study strongly indicates that antioxidant enzymes namely GST, GSHPx and CAT can be used as surrogate markers of oxidative stress for the cirrhosis condition.
\end{abstract}

Key-words: Anthropometric Assessment; Biochemical Parameters; Total Antioxidant Activity; Antioxidant Enzymes; Oxidative Stress Marker
ABBRIVATIONS
BMI: body mass index
WBC: white blood cells
RBC: red blood cells
FBS: fasting blood glucose
HDL: high density lipoprotein
LDL: low density lipoprotein
ALT: Alanine aminotransferase
AST: Aspartate aminotransferase
GGT: $\Upsilon$ - glutamyl transferase
ALP: alkaline phosphatase
GAE: gallic acid equivalent
TE: trolox equivalent
ROS: reactive oxygen species
HCC: hepatocellular carcinoma

\section{INTRODUCTION}

Cirrhosis is defined as the histological development of regenerative nodules surrounded by fibrous bands in response to chronic liver injury that leads to portal hypertension and end-stage liver disease [1, 2]. Hepatic stellate cells have an essential role in the pathogenesis of 
liver fibrosis, due to which they control the matrix degradation in the liver [3].

Impaired liver function, portal hypertension and the progression of hepatocellular carcinoma (HCC) are the main clinical consequences of cirrhosis $[4,2]$. Alcoholic and nonalcoholic fatty liver disease or hepatitis B and hepatitis $\mathrm{C}$ are causative factors of cirrhosis. Patient's history, serologic and histologic evaluation identify the etiology of cirrhosis [2].

Cirrhosis is mounting as a public health problem due to double no of deaths from 5 in 1980 to 9.9 in 2005. Investigation of studies has revealed fatty liver disease in $70 \%$ of overweight and in $35 \%$ of normal weight persons. They have also discovered cirrhosis in $18.5 \%$ of overweight diabetics. Cirrhosis and HCC due to chronic hepatitis $\mathrm{C}$ are the main indicators for liver transplantation in developed countries [5]. Morbidly obese 109 participants followed for nearly 17 years indicates that prevalence of cirrhosis was less than $1 \%$ [6]. Approximately $9 \%$ to $26 \%$ of the participants died in 4 to 10 years of follow-up, with most causes of death linked with the end-stage liver disease [7].

Liver diseases due to excess alcohol ingestion is a major public health problem leading to morbidity and mortality all over the world. The incidence of alcohol consumption is reported as 5-20\% in India. About half of all cirrhosis are alcohol induced and about 10-20\% of all alcoholics are cirrhotic in the world [8].

Moderate alcohol consumption, age above 50 years, and male gender have been described as risk factors in chronic hepatitis C [9]. Obesity at an older age, insulin resistance or type 2 diabetes, hypertension and hyperlipidemia in NASH are etiological factors that contribute to the development of cirrhosis [10]. Excess alcohol consumption increases the risk of progression [5].

Screening tests such as liver transaminases or radiologic findings are useful to diagnose liver diseases, further assessment by a liver biopsy could be necessary for the diagnosis of asymptomatic cirrhosis [2].

The transaminase levels could be in the normal range or only slightly elevated according to [2]. Currently, cirrhosis is not determinable by any biochemical laboratory test [5]. Liver enzymes are insensitive and cannot be used reliably to confirm the diagnosis or stage the extent of fibrosis [11]. Fibroscan can be used as additional tests to screen for the liver diseases. Sometimes, the participants feel healthy and have normal liver function tests, even though they have a liver stiffness greater than $8 \mathrm{kPa}$ suggests that chronic liver disease is present [12].

Oxidative stress and the red cell membrane integrity play a vital role in cell lysis. ROS are generated from metabolism of different endogenous and exogenous compounds, alcohol and viruses. They rapidly react with different molecules and inhibit the cellular function which is involved in the pathogenesis of liver diseases. Insufficient removal of ROS may cause cell damage by attacking membrane lipids, proteins and inactivate enzymes resulted in tissue damage [13]. ROS and lipid peroxidation products are considered as a contributor of onset and development of hepatic fibrosis [14].

The antioxidant enzymes namely superoxide dismutase, catalase, and glutathione peroxidase and non-enzymatic antioxidants (antioxidant vitamins, uric acid, albumin, and bilirubin) help the body to defend against oxygen free radical toxicity [15].

The imbalance between oxidative stress and antioxidants have been observed to result in disturbances of antioxidant mechanisms and increased oxidative stress aggravating liver cirrhosis. As oxidative stress is a crucial factor in the progression of hepatic cirrhosis, efforts were made in the present study to elucidate the changes observed in the selected antioxidants and oxidative stress marker during liver cirrhosis and to evaluate appropriate diagnostic or remedial option.

\section{RELATED WORK:}

Sequential analysis of antioxidant enzymes, total antioxidant activity and oxidative stress marker was not found from the same individual however, some researchers worked on erythrocytes/serum /plasma SOD [15, 16, 17, 18], catalase $[16,18,19]$, GSHPx [16, 19] and MDA [4, 17, 18, 19, 20] in cirrhotic participants. They reported contradictory results. Therefore present study was planned to find out sequential data for total antioxidant activity, selected antioxidant enzymes (SOD, catalase, GSHPx, GST and GR) and oxidative stress marker from human blood samples.

\section{MATERIALS AND METHODS}

\section{Study Design:}

All participants underwent anthropometric assessment, clinical examination, biochemical parameters, antioxidant parameters and oxidative stress marker.

\section{Participant recruitment procedure: Inclusion Criteria:}

Cross-sectional study includes cirrhosis and controls recruited from tertiary centre of gastroenterologist unit, Anand. Controls $(n=52)$ [Participants with normal clinical examination, no symptoms, normal vital signs and has normal biochemical parameters such as blood glucose, lipid profile, liver function test, kidney function test, free of infection at least 30 days prior to the study] and cirrhotic participants $(n=44)$ [diagnosed on the basis of the presence of a history of decompensation, stigmata of the chronic liver disease, portal hypertension on imaging, esophageal varices on endoscopy and cirrhosis on histology] were considered for the study and diagnosed by a gastroenterologist.

\section{Exclusion Criteria:}

Pregnant and lactating women, Alcoholic, Smokers/ tobacco users, Exposure to radiation, Exposure to ozone therapy or hyperbaric oxygen therapy, Exposure to heavy metals or 
ayurvedic medicine, Infection within 30 days, Cancer, Cardiac, gastro-intestinal and brain ischemic disease, Currently not using antioxidant drugs which affect the oxidative stress and antioxidant status were excluded.

\section{Informed Consent:}

Explain interest of the study to the participants and informed consent were taken.

\section{Anthropometric assessment and clinical parameters and biochemical parameters}

Anthropometric assessment includes the record for age, height and weight (Height was measured using height board which is fixed to the wall and weight using high quality electronic digital scale). BMI was calculated using formula $\mathrm{BMI}=[$ body weight $(\mathrm{kg})] /[$ (height $\left.\left.)(\mathrm{m})^{2}\right)\right][21]$.

Measurement of blood pressure (Systolic/Diastolic$(120 / 80))$ was done by sphygmomanometers.

Blood $(6-7 \mathrm{ml})$ was collected from all the participants at fasting condition in plain and EDTA bulb with the help of the laboratory expert. Blood samples were centrifuged at $3000 \mathrm{rpm}$ for $5 \mathrm{~min}$ to separate serum and plasma. Collected samples were analysed immediately for all enzymes, remaining were kept at $4^{\circ} \mathrm{C}$ for other respective parameters. Analysis of the remaining parameters were completed within a week.

Haemogram (Haemoglobin, TC (WBC, RBC and platelets)), Fasting blood glucose, Total Protein, albumin, globulin, lipid parameters such as Cholesterol, TG, LDL, HDL and liver enzymes (SGPT, SGOT, ALP, GGT) were analysed using standard protocols in reputed laboratory.

\section{Antioxidant parameters and oxidative stress marker}

Total antioxidant activity (Gallic acid equivalent and Trolox equivalent) [22] and enzymatic antioxidants (SOD [23], GSHPx [24], CAT [25] and GST [26, 27]) were analysed using standard protocol in our laboratory after crosschecking the standards and samples. U.V. Spectrophotometer (Systronic- model no. 117) was used for investigation of all the above parameters. MDA was analysed from plasma by standard method [28].

\section{Statistical analysis}

Data are expressed as mean \pm S.E. and percentages. Statistical analysis was conducted using t-test.

\section{Ethical approval:}

The institutional ethics committee approved the study protocol with reference No. SANPPGI/HREC/UG/PG/1/2.

\section{RESULTS AND DISCUSSION:}

\section{Anthropometric assessment, clinical parameters and biochemical parameters}

Controls and cirrhotic participants were studied for anthropometric assessment, clinical parameters and biochemical parameters. Values are presented in table: 1.
BMI of the cirrhotic participants for our study is $24.87 \mathrm{~kg} / \mathrm{m}^{2}$ which is nearer to the BMI $\left(24.7 \mathrm{~kg} / \mathrm{m}^{2}\right)$ of cirrhotic participants of Bagalkot [18].

Our study shows a highly significant increase in the serum enzymes (ALT, AST, GGT and ALP) are in accordance with the study carried out by different scientists $[4,8,18,20]$. The increase was only for 42-67\% of the participants (ALT (55\%), AST (67.5\%), GGT (57.5\%) and ALP (42.5\%)). Data is indicated in figure: 1 . Increase in the activities of marker enzymes (AST, GGT) may be due to progression of liver damage [20]. Which can suggest that liver enzymes are insensitive and cannot be used reliably to confirm the diagnosis or stage the extent of fibrosis [11].

\section{Antioxidant parameters and oxidative stress marker}

Antioxidant parameters analysed for our study indicate decrease in total antioxidant activity (Gallic acid equivalent and Trolox equivalent) and antioxidant enzymes (GSHPx, GST and CAT) may be due to defences against free radicalmediated injury includes enzymatic deactivation and direct reaction with free radicals [28, 29].

The percentage decrease for total antioxidant activity [Gallic acid equivalent $(51.8 \%)$ and Trolex equivalent $(70.6 \%)]$ is depicted in figure: 2.

Controls of our study indicates lower value compared to the reference value $[30,31]$, which further decreases (GAE and TE $(P<0.0001))$ among cirrhotic participants.

Antioxidant enzymes such as GSHPx, GST and CAT also decreases however, SOD found increase, these data are illustrated in figure: 3.

Cirrhotic participants indicate decrease in GSHPx is closely related to the study carried out for erythrocyte GSHPx may be due to its association with hemolytic anaemia [16]. Results of our study also indicate lower hemoglobin levels in cirrhotic participants. Low level of catalase and GSHPx reported to decrease erythrocyte protection and cause even greater oxidant stress, predisposing cells to hemolysis [16].

The catalase activity of cirrhotic participants is similar to the study carried out for erythrocytes catalase [16, 18, 19], which could be due to increase in malondialdehyde (MDA) [18].

The increase in serum SOD level in our study is resemble with the study carried out at Turkey [17]. Increase in SOD may be due to the release of injured hepatocytes which decrease lipid peroxidation and lead to detrimental effect on the cellular structures [17] and also indicates disease severity [32].

Oxidative stress plays an essential role in the progression of ALC and ALD [20, 33]. The increases of MDA in our cirrhotic participants is in accordance with the study carried out by various researchers [4, 17, 18, 19, 20, 33]. As oxidative stress increases, antioxidant activity decreases is indicated in figure: 4.

Statistical analysis for antioxidant parameters such as total antioxidant activity (Gallic acid equivalent and Trolox 
Table: 1 Various parameters observed in Controls and cirrhotic participants

\begin{tabular}{|c|c|c|c|c|c|}
\hline \multirow{2}{*}{\multicolumn{2}{|c|}{ Parameters }} & $\begin{array}{c}\text { Controls } \\
(n=52)\end{array}$ & Cirrhosis $(n=44)$ & \multirow[t]{2}{*}{ t value } & \multirow[t]{2}{*}{$\begin{array}{c}\text { Statistical } \\
\text { Significance }\end{array}$} \\
\hline & & Mean & Mean & & \\
\hline \multicolumn{6}{|c|}{ A) Demographic Profile } \\
\hline \multicolumn{2}{|l|}{ Age (Years) } & $\begin{array}{l}26.71 \pm 1.23 \\
(39 \mathrm{M} / 13 \mathrm{~F})\end{array}$ & $\begin{array}{l}53.48 \pm 2.02 \\
(34 \mathrm{M} / 10 \mathrm{~F})\end{array}$ & $11.70 * *$ & $\mathrm{p}<0.001$ \\
\hline \multicolumn{2}{|l|}{ BMI $\left(\mathrm{kg} / \mathrm{m}^{2}\right)$} & $22.28 \pm 0.68$ & $24.85 \pm 0.62$ & $2.74 *$ & $\mathrm{p}<0.05$ \\
\hline \multirow{2}{*}{ Hypertension (mmHg) } & DP & $77.5 \pm 0.61$ & $81.25 \pm 1.39$ & $2.60 *$ & $\mathrm{p}<0.05$ \\
\hline & SP & $115.19 \pm 0.70$ & $127.07 \pm 1.90$ & $6.23 * *$ & $\mathrm{p}<0.0001$ \\
\hline \multicolumn{6}{|c|}{ B) Haematological parameters } \\
\hline \multirow{3}{*}{\multicolumn{2}{|c|}{$\begin{array}{l}\text { Haemoglobin }(\mathrm{gm} / \mathrm{dl}) \\
\text { Total WBC Count }(\text { cells } / \mu \mathrm{l}) \\
\text { Total RBC Count (million } \\
\text { cells } / \mu \mathrm{l})\end{array}$}} & $13.27 \pm 0.18$ & $10.43 \pm 0.40$ & $6.85 * *$ & $\mathrm{p}<0.0001$ \\
\hline & & $7686.15 \pm 188.95$ & $7760.61 \pm 575.89$ & 0.13 & NS \\
\hline & & $4.50 \pm 0.08$ & $3.43 \pm 0.12$ & $7.74 * *$ & $\mathrm{p}<0.0001$ \\
\hline \multicolumn{2}{|c|}{ Platelet Count (cells*10 $1 / \mu \mathrm{l})$} & $3.29 \pm 0.08$ & $1.63 \pm 0.14$ & $10.34 * *$ & $\mathrm{p}<0.0001$ \\
\hline \multicolumn{6}{|c|}{ C) Biochemical parameters } \\
\hline \multirow{4}{*}{\multicolumn{2}{|c|}{$\begin{array}{l}\text { Glucose }(\mathrm{mg} / \mathrm{dl}) \\
\text { Total Protein }(\mathrm{gm} / \mathrm{dl}) \\
\text { Globulin }(\mathrm{gm} / \mathrm{dl}) \\
\text { A/G ratio }\end{array}$}} & $85.87 \pm 1.06$ & $114.47 \pm 6.51$ & $4.69 * *$ & $\mathrm{P}<0.0001$ \\
\hline & & $7.86 \pm 0.03$ & $7.09 \pm 0.14$ & $5.93 * *$ & $\mathrm{p}<0.0001$ \\
\hline & & $3.23 \pm 0.02$ & $3.91 \pm 0.16$ & $4.67 * *$ & $\mathrm{p}<0.0001$ \\
\hline & & $1.44 \pm 0.02$ & $0.95 \pm 0.09$ & $5.98 * *$ & $\mathrm{p}<0.0001$ \\
\hline \multicolumn{6}{|c|}{ D) $\quad$ Lipid profile } \\
\hline \multicolumn{2}{|l|}{ Cholesterol (mg/dl) } & $156.67 \pm 3.62$ & $146.96 \pm 8.25$ & 1.14 & NS \\
\hline \multicolumn{2}{|l|}{ Triglyceride (mg/dl) } & $80.58 \pm 3.35$ & $126.96 \pm 14.22$ & $3.42 * *$ & $\mathrm{p}<0.001$ \\
\hline \multicolumn{2}{|l|}{$\mathrm{HDL}(\mathrm{mg} / \mathrm{dl})$} & $46.60 \pm 1.39$ & $32.83 \pm 2.38$ & $5.17 * *$ & $\mathrm{p}<0.0001$ \\
\hline \multicolumn{2}{|l|}{ LDL (mg/dl) } & $93.61 \pm 3.76$ & $89.66 \pm 7.09$ & 0.51 & NS \\
\hline \multicolumn{2}{|l|}{$\operatorname{VLDL}(\mathrm{mg} / \mathrm{dl})$} & $16.12 \pm 0.67$ & $27.83 \pm 3.33$ & $3.73 * *$ & $\mathrm{P}=0.000$ \\
\hline \multicolumn{2}{|l|}{ Cholesterol/HDL ratio } & $3.48 \pm 0.11$ & $5.72 \pm 0.79$ & $3.04 *$ & $\mathrm{p}<0.05$ \\
\hline
\end{tabular}

Note: DP- Diastolic pressure, SP- Systolic pressure, Values are expressed as \pm S. E. (Standard error), $\mathrm{p}<0.05$ indicates significant level, $\mathrm{p}<0.0001, \mathrm{p}=0.000, \mathrm{p}=0.0001$ and $\mathrm{p}<0.001$ indicates highly significant value, NS indicates non-significant value

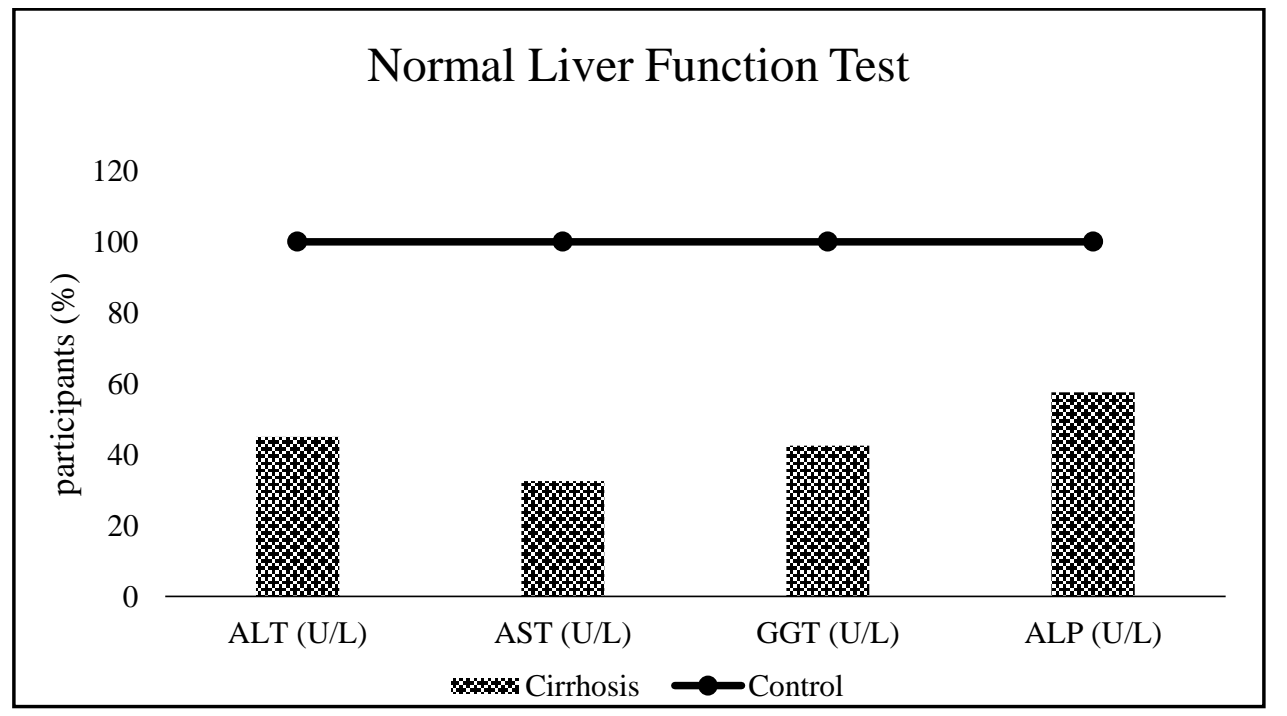

Figure: 1 Percentage of controls and cirrhotic participants for liver function test 


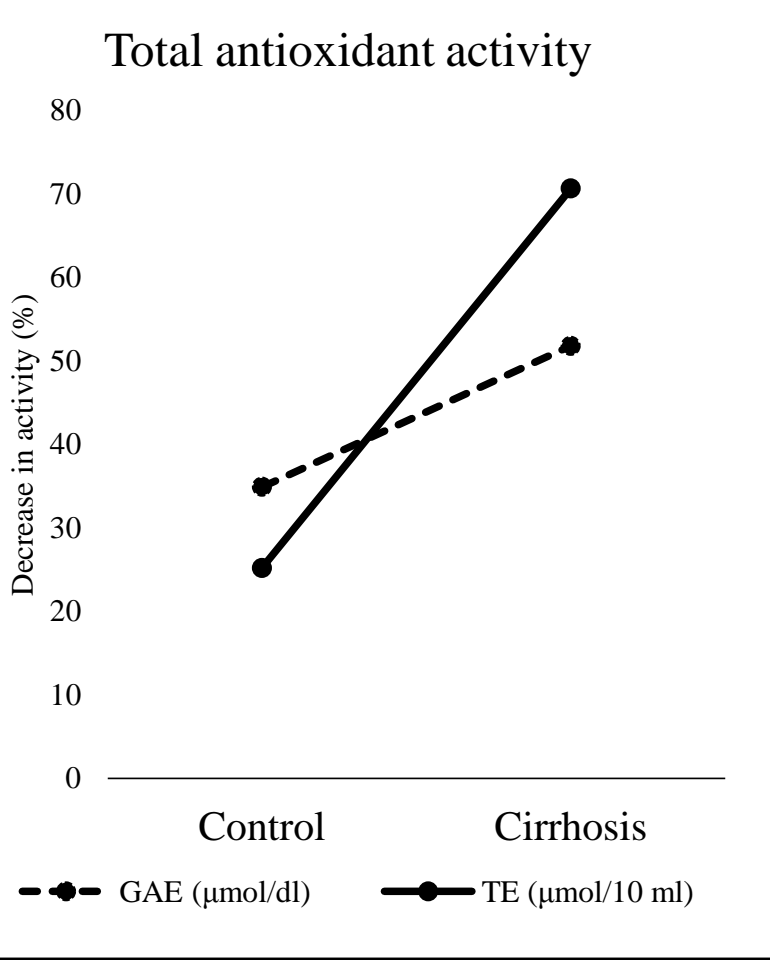

Figure: 2 Total antioxidant activity in terms of GAE and TE of controls and cirrhotic participants

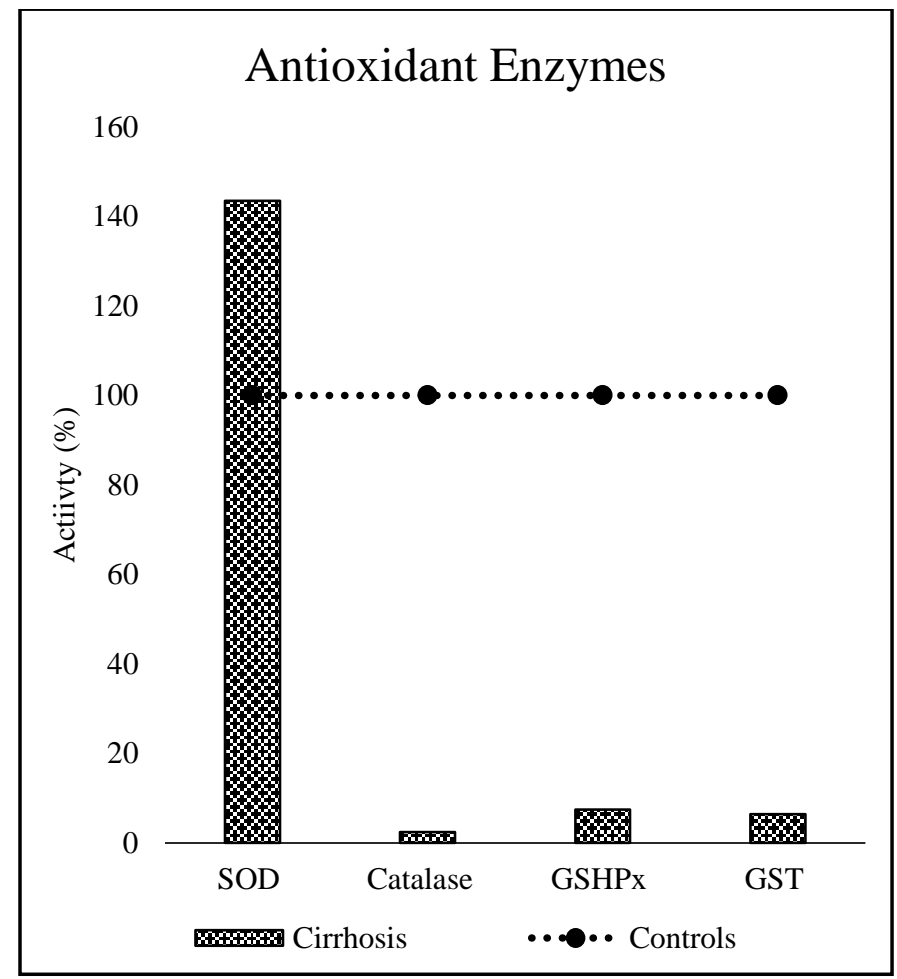

Figure: 3 Antioxidant enzymes SOD, catalase, GSHPx and GST of controls and cirrhotic participants.

Note: SOD $(\mathrm{U} / \mathrm{ml})$, Catalase $((\mu$ moles $/ \mathrm{min} / \mathrm{mg}$ of protein), GSHPx (U/ml), GST (IU/l)

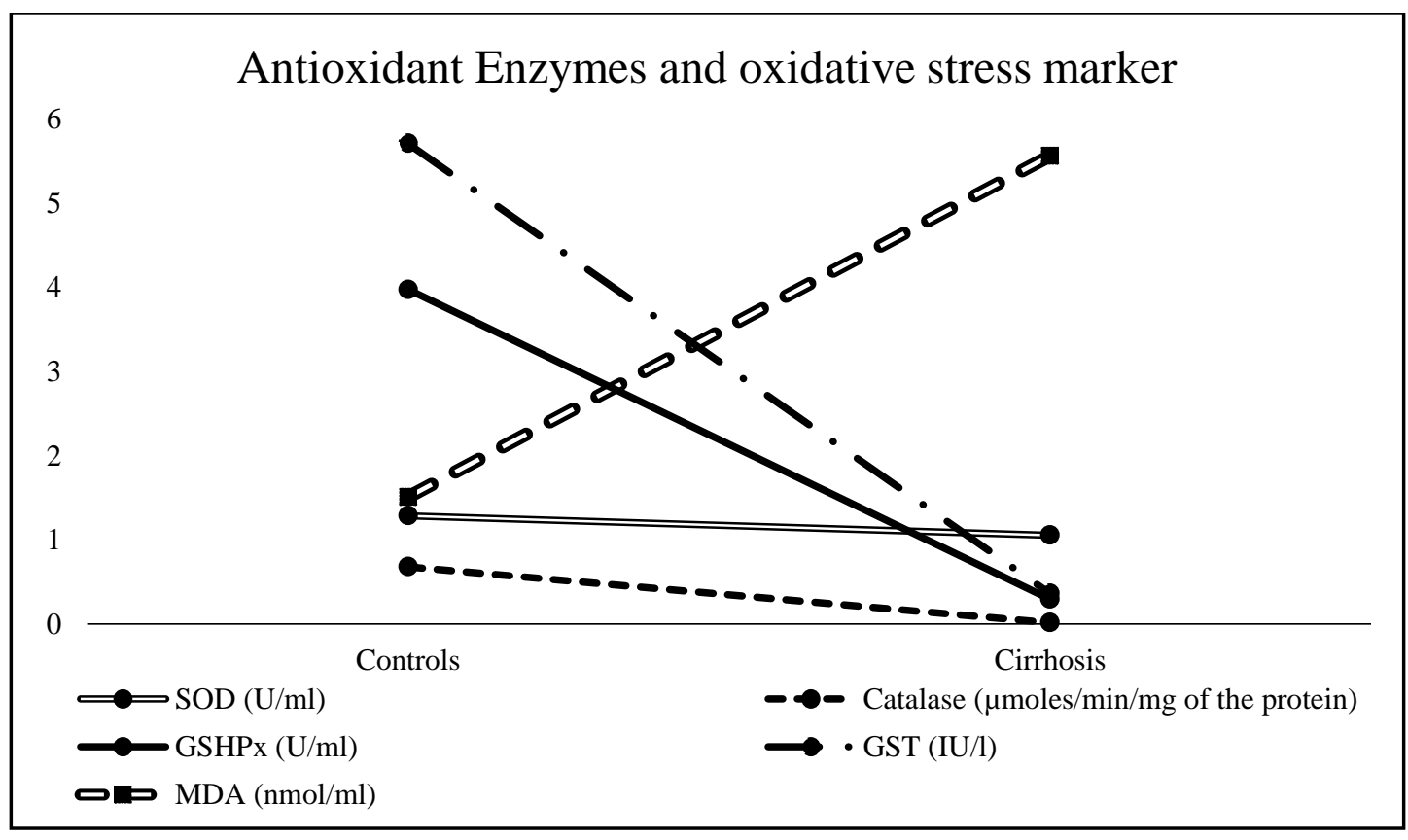

Figure: 4 Comparison of antioxidant enzymes and oxidative stress marker of controls and cirrhotic participants 
Table: 2 Statistical analysis of various parameters for cirrhotic participants

\begin{tabular}{|c|c|}
\hline Parameters & Statistical significance \\
\hline \multicolumn{2}{|c|}{ Total antioxidant activity } \\
\hline $\mathrm{GAE}(\mu \mathrm{mol} / \mathrm{dl})$ & $\mathrm{p}<0.0001$ \\
\hline $\mathrm{TE}(\mu \mathrm{mol} / \mathrm{dl})$ & $\mathrm{p}<0.0001$ \\
\hline \multicolumn{2}{|c|}{ Antioxidant enzymes } \\
\hline $\mathrm{SOD}(\mathrm{U} / \mathrm{ml})$ & $\mathrm{P}<0.05$ \\
\hline CAT $(\mu \mathrm{mol} / \mathrm{min} / \mathrm{mg}$ of protein $)$ & $\mathrm{p}<0.0001$ \\
\hline GSHPx (U/ml) & $\mathrm{p}<0.0001$ \\
\hline GST (U/ml) & $\mathrm{p}<0.0001$ \\
\hline \multicolumn{2}{|c|}{ Oxidative stress marker } \\
\hline MDA (nmol/ml) & $\mathrm{p}<0.0001$ \\
\hline
\end{tabular}

\section{CONCLUSION AND FUTURE SCOPE:}

Antioxidant status for all the cirrhotic participants found poor. Results indicate lower value for antioxidant enzymes such as catalase (93.97\%), GSHPx (93.22\%) and GST $(87.02 \%)$. All the cirrhotic participants showed a decrease in all antioxidant enzymes except SOD $(18.18 \%$ of the participants). Three antioxidant enzymes namely catalase, GST and GSHPx extremely decrease in liver cirrhosis participants may be used as a surrogate markers to diagnose the liver cirrhotic condition. Further study on cirrhosis can be done by evaluating more samples from both the genders with hepatitis $\mathrm{B}$ and $\mathrm{C}$ infection and also at different geographical condition.

\section{LIMITATIONS}

Study is limited for alcoholic and non-alcoholic liver cirrhosis condition except hepatitis B and C. Grouping of the cirrhosis condition on the basis of other disease/disorder conditions such as obesity, diabetes mellitus or any other associated condition is not included in present study.

\section{DISCLOSURE STATEMENT}

The authors have nothing to disclose.

\section{CONFLICT OF INTEREST STATEMENT}

The authors have no conflict of interest regarding the subject of the study.

\section{ACKNOWLEDGMENT}

The authors are grateful to all the participants, without their precious help study was not possible. We thank principal of our institute to provide support and laboratory facilities. We are also thankful to N. D. Patel (M.D., D. N. B. Gastroenterologist) to screen out appropriate participants for the study and S. Patel (Sanjay Laboratory) for blood collection. We also thankful to statistics department, Anand Agriculture University for helping in statistical analysis.

\section{AUTHOR CONTRIBUTION}

H. J. Shah, A. P. Thakkar and N. D. Patel had made efforts to plan out the objectives of the study.

H. J. Shah had guided for the analytical work and interpreted the result of the study.

A. P. Thakkar had collected informed consent from the participants and analysed the parameters from the collected blood samples penetrating to this work. Effort was made to standardize each protocol in our laboratory and computerised and calculate the data.

Dr. N. D. Patel had screen out appropriate participants for the study and guided as per the need.

We all together worked for the preparation of the manuscript.

\section{REFERENCES:}

[1]. M. Ekstedt, L.E. Franzén, U.L. Mathiesen, L. Thorelius, M. Holmqvist, G. Bodemar, S. Kechagias, "Long-term Follow-up of Patients with NAFLD and Elevated Liver Enzymes", Hepatology, Vol. 44, No. 4, pp.865-73, 2006.

[2]. D. Schuppan, N.H. Afdhal, "Liver Cirrhosis", Lancet, Vol. 371, No. 9615, pp. 838-851, 2008.

[3]. R.C. Benyon, M.P. Arthur, "Extracellular Matrix Degradation and the Role of Hepatic Stellate Cells", Semin Liver Dis., Vol. 21, No. 3, pp.373-384, 2001.

[4]. Sheng-Lan. Wang, Xin-Yan. Zhu, Dong-Wei. Zhang, Zhao-Jie. Zhang, H. Gao, Chang-Qing, Yang, "Relevance of Plasma Malondialdehyde Level and Severity of Portal Hypertension in Cirrhotic Patients", Int J Clin Exp Med, Vol. 8, No. 7, pp.11007-11013, 2015.

[5]. J. Wiegand, T. Berg, "The Etiology, Diagnosis and Prevention of Liver Cirrhosis-Part 1 of a Series on Liver Cirrhosis", Dtsch Arztebl Int, Vol. 110, No. 6, pp.85-91, 2013. 
[6]. S. Dam-Larsen, M. Franzmann, I.B. Andersen, P. Christoffersen, L.B. Jensen, , T.I.A. Sorensen, U. Becker, F. Bendtsen, "Long Term Prognosis of Fatty Liver: Risk of Chronic Liver Disease and Death", Gut, Vol. 53, pp.750-755, 2004.

[7]. P. Angulo, "Obesity and Non-Alcoholic Fatty Liver Disease", Nutrition Reviews, Vol. 65, No. 6, pp.S57-S63, 2007.

[8]. P.P. Torkadi, I.C. Apte, A.K. Bhute, "Biochemical Evaluation of Patients of Alcoholic Liver Disease and Non-Alcoholic Liver Disease", Ind. J. Clin Biochem, Vol. 29, No. 1, pp.79-83, 2014.

[9]. T. Poynard, P. Bedossa, P. Opolon, "Natural History of Liver Fibrosis Progression in Patients with Chronic Hepatitis C. The OBSVIRC, METAVIR, CLINIVIR, and DOSVIRC Groups", Lancet, Vol. 349, No. 9055, pp.825-832, 1997.

[10]. G.C. Farrell, C.Z. Larter, "Non-Alcoholic Fatty Liver Disease: From Steatosis to Cirrhosis", Hepatology, Vol. 43, pp.S99S112, 2006.

[11]. B.A. Neuschwander-Tetri, S.H. Caldwell, "Non-Alcoholic Steatohepatitis: Summary of an AASLD Single Topic Conference", Hepatology, Vol. 37, No. 5, pp.1202-19, 2003.

[12]. D. Roulot, J.L. Costes, J.F. Buyck, U. Warzocha, N. Gambier, S. Czernichow, H. Le Clesiau, M. Beaugrand, "Transient Elastography as a Screening Tool for Liver Fibrosis and Cirrhosis in a Community-Based Population Aged Over 45 Years", Gut, Vol. 60, No. 7, pp.977-84, 2011.

[13]. C. Bolukbas, F.F. Bolukbas, M. Horoz, M. Aslan, H. Celik, O. Erel, "Increased Oxidative Stress Associated with the Severity of the Liver Disease in Various Forms of Hepatitis B Virus Infection”, BMC Infectious Diseases, Vol. 5, No. 95, 2005.

[14]. A. Szuster - Ciesielska, J. Daniluk, M. Kandefer - Szerszen, "Oxidative Stress in the Blood of Patients with Alcohol-Related Liver Cirrhosis", Med Sci Monit, Vol. 8, No. 6, pp.CR419 24, 2002.

[15]. M. Koruk, H. Aksoy, F. Akcay, M.D. Onuk, "Antioxidant Capacity and Nitric Oxide in Patients with Hepatic Cirrhosis", Annals of Clinical \& Laboratory Science, Vol. 32, No. 3, pp.252-256, 2002.

[16]. G. Gerli, G.F. Locatelli, R. Mongiat, L. Zenoni, A. Agostoni, G. Moschini, D. Zafiropoulos, S. Bruno, S. Rossi, A. Vignati, G. Tarolo, M. Podda, "Erythrocyte Antioxidant Activity, Serum Ceruloplasmin and Trace Element Levels in Subjects with Alcoholic Liver Disease", Am J Clin Pathol, Vol. 97, pp.614618, 1992.

[17]. S. Ozenirler, B. Sancak, U. Coskun, "Serum and Ascitic Fluid Superoxide Dismutase and Malondialdehyde Levels in Patients with Cirrhosis", Biomarker Insights, Vol. 3, pp.141-145, 2008.

[18]. S. Pujar, S.V. Kashinakunti, K. Gurupadappa, R. Manjula, "Serum MDA, Antioxidant Vitamins and Erythrocytic Antioxidant Enzymes in Chronic Alcoholic Liver Disease - A Case Control Study", Al Ame en J Med Sci., Vol. 4, No.4, pp.315-322, 2011.

[19]. B. Sowjanya, M.N. Kumar, J.N. Naidu, K. Ramalingam, D. Rajarajeswari, "Imbalance of Oxidants and Antioxidant Systems in Subjects with Cirrhosis", International Journal of Applied Biology and Pharmaceutical Technology, Vol. 1, No. 3, pp.1312-1316, 2010.
[20]. M. Galicia-Moreno, D. Rosique-Oramas, Zairamedina-Avila, T. Alvarez-Torres, D. Falcón, Fatima Higuera-De La Tijera, Y.L. Bejar, P. Cordero-Pérez, Lindamuñoz-Espinosa, J.L. Perez-Hernandez, D. Kershenobich, G. Gutierrez-Reyes, "Behavior of Oxidative Stress Markers in Alcoholic Liver Cirrhosis Patients", Oxidative Medicine and Cellular Longevity, pp.1-10, 2016.

[21]. S. Saluja, K. Arora. "Overweight and Obesity and Its Association with Blood Pressure Levels Amongst Females of Bathinda, Punjab", India J. maternal child health physiological dept., Adesh institute of medical science ad research -Bathinda, Vol. 12, pp. 11- 13, 2010.

[22]. I.F. Benzie, J. J. Strains, "The Ferric Reducing Ability of Plasma (FRAP) as a Measure of "Antioxidant Power": The FRAP assay”, Anal Biochem, Vol. 239, pp.70-76, 1996.

[23]. S. Marklund, G. Marklund, "Involvement of the Superoxide Anion Radical in the Autoxidation of Pyrogallol and a Convenient Assay for Superoxide Dismutase", Eur. J. Biochem., Vol. 47, pp.469-474, 1974.

[24]. D.E. Paglia, W.N. Valentine, "Studies on the Quantitative and Qualitative Characterization of Erythrocyte Glutathione Peroxidase", J. Lab Clin. Med, Vol. 70, Issue 1, pp.158-169, 1967.

[25]. H. Aebi, "Catalase in Vitro Methods", Enzymol, Vol. 105, pp. 121-126, 1984.

[26]. E. Beutler, "Red cell metabolism", A Manual of Biochemical Methods, 3rd ed. Grune and Stratton Inc., New York, 1984.

[27]. M.S. Muttigi, V. Kedage, R. Suvarna, S.S. Rao, C. Joshi, M.S. Shetty, M. Prakash,. "Serum GST Activity and Total Thiols Status in Patients with Liver Disease Secondary to Various Disorders", The Open Hepatology Journal, Vol. 1, pp.5-8, 2009.

[28]. K. Asha, H.P. Kedilaya, K. Poomima, M. Cariappa, M. Nandini. "Oxidant and Antioxidant Status in Vegetarians and Fish Eaters", Indian Journal of Clinical Biochemistry, Vol. 18, Issue 2, pp. 197-205, 2003.

[29]. M. Koruk, S. Taysi, M.C. Savas, O. Yilmaz, F. Akcay, M. Karakok, "Oxidative Stress and Enzymatic Antioxidant Status in Patients with Non-alcoholic Steatohepatitis", Annals of Clinical \& Laboratory Science, Vol. 34, Issue 1, pp.57-62, 2004.

[30]. A.P. Thakkar, H.J. Shah, N.D. Patel, J.G. Shah. "Alteration in Antioxidant Defense System and Oxidative Stress in blood for Non Alcoholic Fatty Liver Disease", International Journal of Scientific Research in Biological Sciences, Vol.4, Issue 5, pp.1$10,2017$.

[31]. S.L. Sharma, S.A. Chokshi, D. Desai, H. Mewada, A. Singh, "Non Enzymatic Antioxidants, Malondialdehyde and Total Antioxidant Activity as Markers of Oxidative Stress in Arthritis and Rheumatoid Arthritis", NHL Journal Of Medical Sciences, Vol. 2, Issue 1,pp.57-60, 2013.

[32]. Y. Kambayashi, N.T. Binh, H.W. Asakura, Y. Hibino, Y. Hitomi, H. Nakamura, K. Ogino, "Efficient Assay for Total Antioxidant Capacity in Human Plasma Using a 96-Well Microplate”, J. Clin. Biochem. Nutr., Vol. 44, pp.46-51, 2009.

[33]. S. Kubota, N. Sato, T. Matsumura, T. Kamada, "Chemiluminescence and Superoxide Dismutase in the Plasma 
in Patients with Alcoholic and Non-Alcoholic Liver Injuries", Alcohol, Vol. 2, No. 3, pp.469-472, 1985.

[34]. S. Gupta, R. Pandey, R. Katyal, H.K. Aggarwal, R.P. Aggarwal, S.K. Aggarwal, "Lipid Peroxide Levels and Antioxidant Status in Alcoholic Liver Disease", Indian Journal of Clinical Biochemistry, Vol. 20, No. 1, pp.67-71, 2005.

\section{AUTHORS PROFILE}

A.P. Thakkar pursued M.Sc. in Biochemistry from BRD

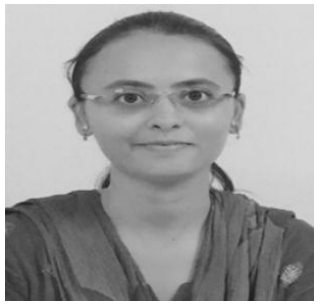
school of Biosciences, Department of Biochemistry, Faculty of Sciences, Sardar Patel University, Vallabh Vidyanagar-Anand, Gujarat, India. She is currently working to pursue her $\mathrm{Ph}$. D. degree and submitted her thesis entitled "Studies on alteration in antioxidant level at various age and selected disease conditions in human blood samples" under the guidance of Dr. (Mrs.) H.J. shah in Department of Biochemistry at M. B. Patel Science College, C. E. Society, Anand, Gujarat. She has published 7 research papers in reputed international and national journals. She has participated and presented more than 19 research papers in oral and poster presentation in various international and national conferences. She had received 6 awards in various international and national conferences for presentations. She had participated in 5 workshops including ICMR and GSBTM supported workshop on Ethical consideration in current research in human participants. Her main research work focuses on Nutritional, Biochemical and clinical parameters related to food, medicinal plants and human blood samples. She has 7.5 years of research experience. She worked for UGC sponsored Major Research Project entitled "Dietary \& Nutritional status of college going adolescent students studying in selected colleges".

H.J. Shah pursued M.Sc. and $\mathrm{Ph}$.D.in Foods and nutrition from Department of Foods and Nutrition, Faculty of Home Sciences, Sardar Patel University, Vallabh Vidyanagar-Anand, Gujarat, India. She is currently working as a Professor in Department of Biochemistry from July, 1982 at M.

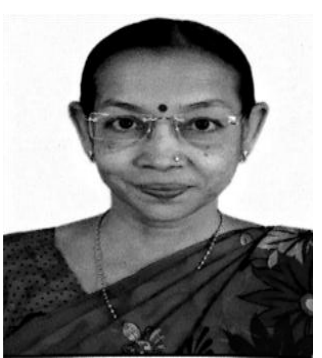

B. Patel Science College, C. E. Society, Anand, Gujarat. She is associate editor of International Journal of Agriculture Sciences and editorial member of Acta Scientific Agriculture Journal. She has published 16 research papers in reputed international and national journals. She has participated and presented more than 25 research papers in oral and poster presentation in various international and national conferences. She had received 7 awards in various international and national conferences for presentations. She had participated in 6 workshops including ICMR and GSBTM supported workshop on Ethical consideration in current research in human participants. Her main research work focuses on Nutritional, Biochemical and clinical parameters related to food, medicinal plants and human blood samples. She has 34 years of teaching experience and 25 years of research experience. She is recognized as Ph.D. guide in Foods and nutrition and Biochemistry since 2008. She has guided 9 students for their research work. She act as a Chairman in Board of study in Biosciences, Sardar Patel University since 2011. She has Organized CBCS syllabi workshop. She is also a member of research committee for the faculty of home science and biosciences. She has received UGC sponsored Major Research Project entitled "Dietary \& Nutritional status of college going adolescent students studying in selected colleges" in 2008. She is acting as external examiner for various P. G. courses of Sardar Patel University and at U. G. level in various universities.

N.D. Patel pursued M.B.B.S. and M.D. (Gastroenterologist) from M. S. University, Baroda, Gujarat, India. He also pursued D.N.B. in gastroenterology from national board of examination, New Delhi. $\mathrm{He}$ is working as a consulting gastroenterologist, Hepatologist and therapeutic endoscopist at

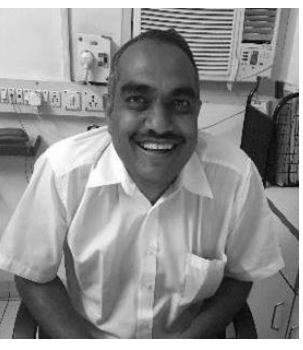
Jiwandeep hospital, Anand, Gujarat, India since 2006. He has published more than 40 research papers in reputed international and national journals. He has presented more than 70 research papers in oral and poster presentation in various international and national conferences. He had participated in more than 100 international and national workshops, seminars and conferences. 